\title{
TOLERÂNCIA AO ALUMÍNIO EM CULTIVARES DE AVEIA BRANCA SOB CULTIVO HIDROPÔNICO ( $\left.{ }^{1}\right)$
}

\author{
JOSÉ ANTONIO GONZALEZ DA SILVA (2*); FERNANDO IRAJÁ FÉLIX DE CARVALHO (3); \\ JEFFERSON LUÍS MEIRELLES COIMBRA $\left({ }^{4}\right)$; EDUARDO ALANO VIEIRA $\left({ }^{5}\right)$; GIOVANI BENIN $\left({ }^{6}\right)$; \\ ANTÔNIO COSTA DE OLIVEIRA $\left({ }^{3}\right)$; TACIANE FINATTO $\left({ }^{3,7}\right)$; IVANDRO BERTAN $(3,8)$, \\ GIOVANI OLEGÁRIO DA SILVA $\left({ }^{9}\right)$; MAICON RUBIRA CORREA $\left({ }^{3,10}\right)$
}

\begin{abstract}
RESUMO
O emprego do cultivo hidropônico para avaliar a tolerância à toxicidade pelo alumínio em genótipos de aveia pode ser feito por meio da medida da retomada do crescimento de raiz. Avaliaram-se 12 cultivares de aveia branca indicadas para o cultivo no Sul do Brasil com o intuito de caracterizar a tolerância ao alumínio, de maneira a ser estrategicamente recomendadas e/ou incluídas em blocos de cruzamento na obtenção de constituições genéticas de elevado potencial produtivo e tolerante ao íon metálico. Foram utilizadas doses de 10, 15 e $20 \mathrm{mg} \mathrm{L}^{-1}$ de alumínio na solução hidropônica e o delineamento experimental adotado foi o completamente casualizado, com três repetições, seguindo o esquema fatorial (12 x 3). As doses empregadas são altamente eficientes na identificação de genótipos de aveia tolerantes e sensíveis ao alumínio tóxico. As cultivares UPF 16, URS 21, UFRGS 14, UPF 19 e UFRGS 17 expressam tolerância.
\end{abstract}

Palavras-chave: Avena sativa L., solução nutritiva, melhoramento genético, retomada do crescimento de raiz.

\section{ABSTRACT \\ TOLERANCE TO THE ALUMINUM IN OAT CULTIVARS UNDER HYDROPONIC CULTURE}

The use of hidroponic culture to evaluate tolerance to aluminum toxicity in oat genotypes can be performed by measuring root regrowth, allowing phenotypically to discriminate tolerant genetic constitutions sensitivity. Twelve white oat cultivars indicated for cultivation in Southern Brazil were evaluated aiming at to characterize their aluminum tolerance, in order to use them as parents in crosses or to recommend them for in cultivation regions. Aluminum concentration of 10, 15 and $20 \mathrm{mg} \mathrm{L}^{-1} \mathrm{were}^{-}$ used in the hydroponic solution arranged in complete randomized blocks with three replications in $12 \mathrm{x}$ 3 factorial designs. Concentrations of 10,15 and $20 \mathrm{mg} \mathrm{L}^{-1}$ were highly efficient for the identification of tolerant and sensitive oat genotypes. Cultivars UPF 16, URS 21, UFRGS 14, UPF 19 and UFRGS 17 showed aluminum.

Key words: Avena sativa L., nutritive solution, genetic improvement, root growth recapture.

$\left({ }^{1}\right)$ Recebido para publicação em 5 de outubro de 2004 e aceito em 4 de junho de 2007.

$\left({ }^{2}\right)$ Departamento de Estudos Agrário/Curso de Agronomia, Universidade Regional do Noroeste do Estado do Rio Grande do Sul (UNIJUÍ), Rua do Comércio, 3000, Bairro Universitário, 98700-000 Ijuí (RS). E-mail: jagsfaem@yahoo.com.br $\left(^{*}\right)$ Autor correspondente.

$\left({ }^{3}\right)$ Centro de Genômica e Fitomelhoramento, Faculdade Eliseu Maciel (FAEM), Universidade Federal de Pelotas (UFPel. Caixa Postal 354, 96010-900 Pelotas (RS). E-mail: carvalho@ufpel.tche.br; acostol@terra.com.br; ivandrobertan@yahoo.com.br maiconrubira@yahoo.com.br

$\left({ }^{4}\right)$ Centro Agroveterinário (CAV), Universidade do Estado de Santa Catarina, Caixa Postal 281, 88520-000, Lages (SC). E-mail: coimbrajefferson@cav.udesc.br

$\left({ }^{5}\right)$ Embrapa Cerrados, Caixa Postal 08223, 73310-970 Planaltina (DF). E-mail: vieiraea@cpac.embrapa.br

$\left({ }^{6}\right)$ Universidade Tecnológica Federal do Paraná (UTFPR). Caixa Postal s/n, 85503-390 Pato Branco (PR). Email: benin@utfpr.edu.br;

$\left({ }^{7}\right)$ Bolsista CNPq-PIBIC/UFPel.

$\left({ }^{8}\right)$ Bolsista CAPES/UFPel.

$\left({ }^{9}\right)$ Embrapa Hortaliças, Caixa Postal 218, 70359-970 Brasília (DF). E-mail: olegário@cnph.embrapa.br

$\left({ }^{10}\right)$ Bolsista de Projeto “Melhoramento Genético de Cereais de Estação Fria”, FAEM/UFPel. Email: maiconrubira@yahoo.com.br 


\section{INTRODUÇÃO}

Na maioria dos solos brasileiros, os teores de alumínio freqüentemente atingem níveis tóxicos para as plantas. Sua toxicidade é, em geral, o fator limitante no aumento da produtividade das culturas em solos ácidos, e seu efeito manifesta-se pela limitação no desenvolvimento do sistema radicular, bem como por sua interferência na absorção, transporte e utilização de nutrientes (SIlva et al., 1984). A absorção e o acúmulo desse elemento em diferentes partes da planta afetam células e organelas em nível morfológico, citogenético e fisiológico, prejudicando consideravelmente o desenvolvimento de genótipos sensíveis (KumAR et al., 1995).

No Brasil, os primeiros sintomas do efeito tóxico do alumínio foram relatados por BECKMANN (1954) nas culturas de trigo e outros cereais de inverno. Esse autor observou o amarelecimento e a redução de crescimento da parte aérea dessas espécies, aos quais denominou "crestamento". Os trabalhos visando ao melhoramento genético para tolerância ao alumínio, entretanto, são descritos internacionalmente na literatura desde 1925.

A obtenção de elevado rendimento de grãos em aveia, em solos com níveis de alumínio considerados tóxicos, exige a correção da acidez ou o emprego de genótipos tolerantes. De acordo com Oliveira (2002), a alternativa mais promissora para reduzir os efeitos tóxicos do alumínio no solo é a exploração do potencial genético das culturas, pois as espécies e variedades diferem amplamente na tolerância ao excesso do elemento no solo.

A avaliação em campo para reação ao alumínio tóxico é a mais utilizada pelos melhoristas, principalmente por possibilitar adaptação gradativa dos genótipos ao ambiente e permitir, de maneira direta, a seleção múltipla em vários caracteres de interesse agronômico. A seleção para tolerância ao alumínio, entretanto, é dificultada pela heterogeneidade dos solos e demais variações de ambiente, pois não permite isolar de modo efetivo o dano causado pelo estresse desse elemento, e pela dificuldade de avaliar danos na raiz, o que induz a erros consideráveis na identificação de constituições genéticas tolerantes.

A reação das plantas ao alumínio pode ser detectada e medida por meio de diferentes parâmetros em testes a campo, em casa de vegetação ou em laboratório. Desse modo, aferições da massa seca da parte aérea e das raízes, da translocação de $\mathrm{P}$ das raízes para a parte aérea, comprimento de raízes, comprimento relativo da raiz e retomada do crescimento de raiz, podem estabelecer diferenças entre genótipos sensíveis e tolerantes (SANCHÉZ-CHÁCON et al., 2000).

Uma técnica eficaz para avaliar a tolerância a toxicidade ao alumínio tem sido o emprego do cultivo hidropônico utilizando soluções nutritivas em laboratório, e a identificação da sensibilidade do genótipo pela da medida da retomada do crescimento de raiz (Moore et al., 1976). Desse modo, medindo a retomada do crescimento de raiz após o tratamento com alumínio, é possível separar fenotipicamente os genótipos com tolerância ou sensíbilidade (CAMARGO e Oliveira, 1981; Aniol, 1990; Minella e Sorrels, 1992; Riede e Anderson, 1996; Benin et al., 2004).

O objetivo do presente trabalho foi caracterizar diferentes cultivares de aveia branca recomendadas para cultivo no Sul do Brasil, quanto à tolerância ao alumínio tóxico com o emprego de cultivo hidropônico, utilizando como indicador a mensuração do caráter retomada do crescimento de raiz.

\section{MATERIAL E MÉTODOS}

Em 2003, doze cultivares de aveia branca, recomendadas pela Comissão Brasileira de Pesquisa de Aveia, foram empregadas para avaliar os níveis de tolerância à toxicidade pelo alumínio. $\mathrm{O}$ experimento foi desenvolvido no laboratório de Di-haplóides e Hidroponia, pertencente ao Centro de Genômica e Fitomelhoramento da Faculdade de Agronomia Eliseu Maciel - Universidade Federal de Pelotas, utilizandose a técnica de cultivo hidropônico descrita por CAmargo e Oliveira (1981) e adaptada por Dornelles et al. (1997).

O delineamento experimental adotado foi o de blocos ao acaso seguindo um esquema fatorial genótipo $x$ dose $(12 \times 3)$ com três repetições. As cultivares de aveia foram testadas em três doses de alumínio, sendo elas, 10, 15 e $20 \mathrm{mg} \mathrm{L}^{-1}$. As sementes de aveia foram desinfestadas com hipoclorito de sódio ( $20 \%$ do produto comercial e $80 \%$ água) por cinco minutos e lavadas com água destilada para retirar o excesso do produto. Após, foram colocadas em Gerbox e levadas a BOD, com temperatura de $20^{\circ} \mathrm{C}$ e com iluminação permanente (lâmpadas fluorescentes de $20 \mathrm{~W}$ ), por 48 horas, para reinício da germinação.

As sementes germinadas de aveia, com aproximadamente $5 \mathrm{~mm}$ de raiz, foram transferidas para uma tela plástica adaptada à tampa de um balde de 5,5 L contendo solução nutritiva. Cada recipiente foi representado por uma cultivar com sua respectiva dose de alumínio, sendo avaliada dez plântulas de cada cultivar. Os baldes foram colocados em tanque 
de metal para que ficassem em banho-maria à temperatura de $25^{\circ} \mathrm{C}$ e iluminação permanente, e ligados a um sistema de aeração para fornecer oxigênio às raízes.

Obteve-se a solução nutritiva padrão com a diluição em 5,5 L de água destilada: $65 \mathrm{~mL}$ de $\mathrm{Ca}\left(\mathrm{NO}_{3}\right)_{2} \cdot 4 \mathrm{H}_{2} \mathrm{O} 78,4$ g. L $\mathrm{L}^{-1} ; 65 \mathrm{~mL}$ de $\mathrm{MgSO}_{4} \cdot 7 \mathrm{H}_{2} \mathrm{O}$ 40,92 g. $\mathrm{L}^{-1} ; 65 \mathrm{~mL}$ de $\mathrm{KNO}_{3} 33,57$ g. $\mathrm{L}^{-1} ; 65 \mathrm{~mL}$ de $\left(\mathrm{NH}_{4}\right)_{2} \mathrm{SO}_{4} 4,77$ g. $\mathrm{L}^{-1} ; 65 \mathrm{~mL} \mathrm{KH}{ }_{2} \mathrm{PO}_{4} 65$ g.L $\mathrm{L}^{-1} ; 6,5 \mathrm{~mL}$ de Fe-EDTA 43,25 g. $\mathrm{L}^{-1}$ e $65 \mathrm{~mL}$ da solução de micronutrientes que é formada pela adição de: $10 \mathrm{~mL}$ de $\mathrm{H}_{3} \mathrm{BO}_{3}$ 0,05146 g. $\mathrm{L}^{-1} ; 1 \mathrm{~mL}$ de $\mathrm{Na}_{2} \mathrm{MoO}_{4} \cdot 2 \mathrm{H}_{2} \mathrm{O}$ 0,00201 g. $\mathrm{L}^{-1} ; 10 \mathrm{~mL}$ de $\mathrm{NaCl} 0,14567 \mathrm{~g} . \mathrm{L}^{-1} ; 1 \mathrm{~mL}$ de $\mathrm{ZnSO}_{4} .7 \mathrm{H}_{2} \mathrm{O} 0,01906$ g. $\mathrm{L}^{-1} ; 1 \mathrm{~mL}$ de $\mathrm{CuSO}_{4} \cdot 5 \mathrm{H}_{2} \mathrm{O}$ 0,00623 g. $\mathrm{L}^{-1}$ e $1 \mathrm{~mL}$ de $\mathrm{MnSO}_{4} \cdot \mathrm{H}_{2} \mathrm{O} 0.03702$ g. $\mathrm{L}^{-1}$ a 2 $\mathrm{L}$ de água destilada. Ao completar 48 horas em solução nutritiva, as tampas com as plântulas foram transferidas para solução nutritiva com alumínio nas concentrações de 10,15 e $20 \mathrm{mg} \mathrm{L}^{-1}$, permanecendo por 48 horas e retornando às soluções nutritivas normais por mais 72 horas. No preparo desta solução-tratamento, utilizaram-se $10 \%$ da concentração- padrão, porém, não incluído o $\mathrm{KH}_{2} \mathrm{PO}_{4}$ para evitar a possível precipitação do alumínio quando se adiciona esta substância à solução nutritiva $10 \%$. Além disso, substituiu-se também a fonte de Fe pelo $\mathrm{FeSO}_{4}$, pois, em presença de alumínio, o Fe-EDTA tende a precipitar.
A avaliação do caráter tolerância ao alumínio tóxico foi efetuada pela medição da retomada do crescimento da raiz (REC) com uma régua, a partir do ponto de dano causado pela toxicidade do alumínio na raiz principal (SILVA et al., 2004). Os dados obtidos foram submetidos à análise de variância e teste de Tukey visando classificar os genótipos após a fixação do fator de interesse. Foram estimados e avaliados, também, os modelos de regressão para o ajuste e a interpretação dos dados, conforme o modelo proposto por STEel e TORRIE (1980).

\section{RESULTADOS E DISCUSSÃO}

O desenvolvimento de um método eficiente para caracterização de genótipos com tolerância ao alumínio é o primeiro passo para a realização de estudos de mecanismos genéticos envolvidos na herança do caráter. Desse modo, o resumo da análise de variância apresentada na tabela 1 , permite verificar que os genótipos testados, as diferentes doses de alumínio, bem como a interação entre os dois fatores foram significantes a $1 \%$ para o caráter REC. Por existir interação genótipo $x$ dose, a análise prosseguiu de a fim de verificar a variação genotípica para cada um dos níveis do fator doses (Tabela 1). Evidenciouse a existência de diferenças entre os genótipos estudados dentro de cada dose.

Tabela 1. Resumo da análise de variância para o caráter retomada do crescimento de raiz (REC) de doze cultivares de aveia em diferentes doses de alumínio na solução e de forma individual fixando o fator dose, FAEM/UFPel, 2004.

\begin{tabular}{|c|c|c|c|c|}
\hline Fonte de Variação & GL & $\mathrm{QM}_{\mathrm{REC}}$ & Média Geral & $\mathrm{CV}$ \\
\hline & & & $\mathrm{mm}$ & $\%$ \\
\hline Modelo & 35 & 65,22 & 9,70 & 7,71 \\
\hline Dose & 2 & $514,85^{* *}$ & - & - \\
\hline Genótipo & 11 & $95,553^{* *}$ & - & - \\
\hline Dose x Genótipo & 22 & $9,182^{* *}$ & - & - \\
\hline Erro & 72 & 0,560 & - & - \\
\hline Total & 107 & - & - & - \\
\hline Fixando o Fator Dose & & $\mathrm{QM}_{\mathrm{REC} 10 \mathrm{mg} \mathrm{L}} \mathrm{L}^{-1}$ & $\mathrm{QM}_{\mathrm{REC} 15 \mathrm{mg} \mathrm{L}}{ }^{-1}$ & $\mathrm{QM}_{\mathrm{REC} 20 \mathrm{mg} \mathrm{L}}{ }^{-1}$ \\
\hline Genótipo/Dose & 11 & $51,93^{* *}$ & $37,92^{* *}$ & $24,06^{* *}$ \\
\hline Erro & 24 & 0,62 & 0,62 & 0,44 \\
\hline Total & 35 & - & - & - \\
\hline Média (mm) & - & 13,63 & 9,37 & 6,08 \\
\hline $\mathrm{CV}(\%)$ & - & 5,77 & 8,38 & 10,90 \\
\hline
\end{tabular}

** Significativo a $1 \%$ de probabilidade de erro pelo teste $\mathrm{F}$;

$\mathrm{QM}_{\mathrm{REC}}=$ Quadrado médio da retomada do crescimento de raiz; $\mathrm{mm}=$ milímetros . 
Tabela 2. Retomada do crescimento de raiz (REC) em milímetros, de 12 cultivares de aveia submetidas a três concentrações de alumínio em cultivo hidropônico, FAEM/UFPel, 2004

\begin{tabular}{|c|c|c|c|}
\hline \multirow{2}{*}{ Genótipo } & \multicolumn{3}{|c|}{ Concentração de Alumínio (mg L $\left.{ }^{-1}\right)$} \\
\hline & 10 & 15 & 20 \\
\hline UPF 16 & 17,16 a $\mathrm{A}$ & $12,16 \mathrm{~b} \mathrm{~B}$ & $6,86 \mathrm{bcd} \mathrm{C}$ \\
\hline OR 2 & 17,23 a $\mathrm{A}$ & $11,66 \mathrm{~b} \mathrm{~B}$ & 7,83 bc C \\
\hline UFRGS 14 & 16,00 a $\mathrm{A}$ & 10,16 bcd $-B$ & $8,30 \mathrm{~b} \mathrm{~B}$ \\
\hline URS 21 & 16,50 a $\mathrm{A}$ & $11,50 \mathrm{~b} \mathrm{~B}$ & 6,00 cde C \\
\hline UPF 19 & 16,33 a $\mathrm{A}$ & 16,00 a $\mathrm{A}$ & 12,33 a B \\
\hline UFRGS 19 & 16,66 a $\mathrm{A}$ & $9,03 \mathrm{~cd} \mathrm{~B}$ & 4,50 ef $\mathrm{C}$ \\
\hline UFRGS 17 & 16,03 a $\mathrm{A}$ & $8,00 \mathrm{~d} B$ & 8,26 b B \\
\hline UFRGS 16 & $12,83 \mathrm{~b} \mathrm{~A}$ & 11,16 bc A & 5,43 ef $B$ \\
\hline UFRGS 15 & $13,16 \mathrm{~b} \mathrm{~A}$ & $8,03 \mathrm{~d} B$ & $4,36 \mathrm{f} \mathrm{C}$ \\
\hline UFRGS 7 & 9,00 с A & $7,93 \mathrm{~d} B$ & 4,16 ef $B$ \\
\hline ALBASSUL & $6,33 \mathrm{~d} A$ & 3,66 e $B$ & $1,96 \mathrm{~g} \mathrm{C}$ \\
\hline UPF 14 & $6,33 \mathrm{~d} A$ & 3,43 e $B$ & $3,03 \mathrm{~g} \mathrm{~B}$ \\
\hline Dms (mm) & 2,31 & 2,31 & 1,95 \\
\hline
\end{tabular}

Médias seguidas por uma mesma letra minúscula nas colunas e nas linhas não diferem significativamente pelo teste de TuKey a $5 \%$; Dms = Diferença mínima significativa.

Os resultados observados na tabela 2 demonstram que para determinados genótipos, a toxicidade do alumínio provocou redução significativa na REC à medida que se elevou sua concentração (UPF16, OR2, URS 21, UFRGS 19, UFRGS 15 e ALBASSUL). No entanto, genótipos como UPF 19, UFRGS16 e UFRGS 7 evidenciaram comportamento similar em 10 e $15 \mathrm{mg} \mathrm{L}^{-1}$ do íon metálico na solução. As cultivares UFRGS14, UFRGS 17 e UPF 14, na dose mais elevada (15 e $20 \mathrm{mg} \mathrm{L}^{-1}$ de alumínio), expressaram o mesmo comportamento. Contudo, os resultados evidenciaram que quanto maiores as doses de alumínio, maior foi o número de classes, discriminando de maneira efetiva a tolerância e sensibilidade das cultivares. Estudando a tolerância ao $\mathrm{Al}^{3+}$ em trigo com o emprego de cultivo hidropônico, BERTAN et al. (2005) classificaram as cultivares de trigo em tolerantes, intermediárias e sensíveis, adicionando-se $10 \mathrm{mg} \mathrm{L}^{-1}$ de alumínio na solução. Entretanto, SÁNCHES-CHÁCON et al. (2000) verificaram que em aveia a variabilidade fenotípica foi expressa a partir de $10 \mathrm{mg} \mathrm{L}^{-1}$ de alumínio na solução, porém, a dose de $20 \mathrm{mg} \mathrm{L}^{-1}$ foi a dose que melhor discriminou os 21 genótipos testados.

Na dose de $10 \mathrm{mg} \mathrm{L}^{-1}$ de alumínio ocorreu a formação de quatro classes distintas. As cultivares UPF 16, OR2, UFRGS 14, URS 21, UPF 19, UFRGA 19 e UFRGS 17 apresentaram os melhores REC, não diferindo entre si, porém, estatisticamente diferentes do grupo dos genótipos UFRGS 15 e UFRGS 16 de classe (b); UFRGS 7 (c); e, ALBASSUL e UPF 14, que revelaram maior sensibilidade ao alumínio na solução. $\mathrm{Na}$ dose de $15 \mathrm{mg} \mathrm{L}^{-1}$ de alumínio, notou-se na cultivar UPF 19 a maior REC, diferindo dos demais na formação de única classe (a). Os genótipos UPF 16, OR 2, UFRGS 14, URS 21 e UFRGS 16 também apresentaram tolerância ao alumínio, não diferindo entre si, enquanto as cultivares ALBASSUL e UPF 14 evidenciaram elevada sensibilidade. Da mesma forma, na concentração de $20 \mathrm{mg} \mathrm{L}^{-1}$, o genótipo UPF 19, que também apresentou o melhor desempenho em relação aos demais, representando a classe (a) e os genótipos UPF 16, OR 2, UFRGS 14 e UFRGS 17 formaram o grupo dois (b) de maior tolerância, seguido dos genótipos UPF 16, OR 2 e URS 21 na formação do terceiro grupo. Além disso, os genótipos URS 21, UFRGS 19, UFRGS 16, UFRGS 15 e UFRGS 7 representaram o segundo grupo de menor REC para o caráter em estudo. Em todas as doses de alumínio, os genótipos ALBASSUL e UPF 14 foram os mais sensíveis ao elemento.

BERTAN et al. (2005), estudando trigos originados da Região Sul do Brasil, determinaram que os genótipos classificados como mais tolerantes eram provenientes de programas de melhoramento de áreas de elevada acidez, confirmando a hipótese de ANDRADE (1976), de que a tolerância ao alumínio pode estar intimamente ligada à origem de cada genótipo e um genótipo desenvolvido sem pressão de seleção, dificilmente, terá em sua constituição genes para o caráter. No entanto, em genótipos como UPF 16 e UPF 14 provenientes do Programa de Melhoramento 
Genético de Aveia, desenvolvido no município de Passo Fundo (RS), região com elevada concentração do íon metálico no solo (FLoss et al., 1983), observaram elevada sensibilidade ao alumínio em comparação a genótipos selecionados em solos com elevada acidez, indicando, sobremaneira, ser a genealogia dos genitores envolvidos no cruzamento determinante para expressão deste caráter nas futuras cultivares.

O resumo da análise de regressão para a variável dependente REC de cada cultivar em função das doses de alumínio estão apresentadas na Tabela 3. Foi observado resposta linear dos cultivares UPF 16, OR 2, URS 21, UFRGS 15, UFRGS 7 e ALBASSUL à aplicação das doses de alumínio na solução, apresentando coeficientes de regressão $\left(b_{i}\right)$ de $-0,85$, $1,98,-0,75,-1,76,-1,13$ e $-1,01$, respectivamente, conforme os dados da Tabela 3 e, como os valores do coeficiente angular da reta foram negativos, estes indicam que o caráter REC apresenta redução com o aumento da dose de alumínio na solução até a paralisação total.

Tabela 3. Resultados da análise de variação da regressão para a variável dependente retomada do crescimento de raiz (REC) em cultivares de aveia para os testes de significância dos componentes linear e quadrático da variação atribuível ao efeito de doses alumínio em solução nutritiva, FAEM/UFPel, 2004.

\begin{tabular}{|c|c|c|c|c|c|c|c|}
\hline Genótipo & Fonte de Variação & GL & $\mathrm{QM}_{\mathrm{REC}}$ & $\mathrm{R}^{2}$ & Estimativa & Valor & $\operatorname{Pr}>|t|$ \\
\hline & & & & & $\left(b_{\mathrm{i}}\right)$ & $(\mathrm{t})$ & \\
\hline \multirow[t]{3}{*}{ UPF 16} & Linear & 1 & $159,13^{*}$ & 0,97 & $-0,85$ & $-1,13$ & 0,30 \\
\hline & Quadrático & 1 & $0,04^{\mathrm{ns}}$ & - & $-0,006$ & $-0,24$ & 0,81 \\
\hline & Erro & 6 & 0,77 & - & - & - & - \\
\hline \multirow[t]{3}{*}{ OR 2} & Linear & 1 & $132,54^{*}$ & 0,97 & $-1,98$ & $-3,24$ & 0,01 \\
\hline & Quadrático & 1 & $1,50^{\mathrm{ns}}$ & - & 0,03 & 1,71 & 0,13 \\
\hline & Erro & 6 & 0,51 & - & - & - & - \\
\hline \multirow[t]{3}{*}{ UFRGS 14} & Linear & 1 & $88,93^{*}$ & 0,95 & $-0,77$ & $-4,15$ & 0,006 \\
\hline & Quadrático & 1 & $7,86^{*}$ & - & 0,07 & 3,15 & 0,01 \\
\hline & Erro & 6 & 0,79 & - & - & - & - \\
\hline \multirow[t]{3}{*}{ URS 21} & Linear & 1 & $165,37^{*}$ & 0,97 & $-0,75$ & $-1,02$ & 0,34 \\
\hline & Quadrático & 1 & $0,12^{\text {ns }}$ & - & $-0,01$ & $-0,41$ & 0,69 \\
\hline & Erro & 6 & 0,75 & - & - & - & - \\
\hline \multirow[t]{3}{*}{ UPF 19} & Linear & 1 & $24,00^{*}$ & 0,85 & 1,60 & 2,09 & 0,08 \\
\hline & Quadrático & 1 & $5,55^{*}$ & - & $-0,06$ & $-2,63$ & 0,03 \\
\hline & Erro & 6 & 0,80 & - & - & - & - \\
\hline \multirow[t]{3}{*}{ UFRGS 19} & Linear & 1 & $222,04^{*}$ & 0,99 & $-1,21$ & $-7,05$ & 0,0004 \\
\hline & Quadrático & 1 & 4,80 * & - & 0,06 & 4,28 & 0,005 \\
\hline & Erro & 6 & 0,26 & - & - & - & - \\
\hline \multirow[t]{3}{*}{ UFRGS 17} & Linear & 1 & $90,48^{*}$ & 0,97 & 5,75 & $-10,01$ & 0,001 \\
\hline & Quadrático & 1 & $34,44^{*}$ & - & 0,16 & 8,70 & 0,001 \\
\hline & Erro & 6 & 0,45 & - & - & - & - \\
\hline \multirow[t]{3}{*}{ UFRGS 16} & Linear & 1 & $82,14^{*}$ & 0,97 & 1,70 & 3,28 & 0,01 \\
\hline & Quadrático & 1 & $8,26^{*}$ & - & $-0,08$ & $-4,73$ & 0,003 \\
\hline & Erro & 6 & 0,37 & - & - & - & - \\
\hline \multirow[t]{3}{*}{ UFRGS 15} & Linear & 1 & $116,16^{*}$ & 0,97 & $-1,76$ & $-3,03$ & 0,02 \\
\hline & Quadrático & 1 & $1,07^{\mathrm{ns}}$ & - & 0,03 & 1,52 & 0,17 \\
\hline & Erro & 6 & 0,46 & - & - & - & - \\
\hline \multirow[t]{3}{*}{ UFRGS 7} & Linear & 1 & $35,04^{*}$ & 0,88 & 1,13 & 1,43 & 0,201 \\
\hline & Quadrático & 1 & $3,64^{\mathrm{ns}}$ & - & $-0,05$ & $-2,05$ & 0,08 \\
\hline & Erro & 6 & 0,86 & - & - & - & - \\
\hline \multirow[t]{3}{*}{ ALBASSUL } & Linear & 1 & $28,601^{*}$ & 0,93 & $-1,01$ & $-2,03$ & 0,08 \\
\hline & Quadrático & 1 & $0,46^{\mathrm{ns}}$ & - & 0,01 & 1,16 & 0,28 \\
\hline & Erro & 6 & 0,34 & - & - & - & - \\
\hline \multirow[t]{3}{*}{ UPF 14} & Linear & 1 & $16,33^{*}$ & 0,90 & $-1,83$ & $-3,72$ & 0,009 \\
\hline & Quadrático & 1 & $3,12^{*}$ & - & 0,05 & 3,00 & 0,02 \\
\hline & Erro & 6 & 0,33 & - & - & - & - \\
\hline
\end{tabular}

\footnotetext{
* Significativo a $5 \%$ de probabilidade de erro pelo teste $\mathrm{F} ; \mathrm{QM}_{\mathrm{REC}}=$ Quadrado médio da retomada do crescimento de raiz.
} 
O valor b (Tabela 3) é a tangente trigonométrica do ângulo que a reta forma com o eixo $\mathrm{X}$, denominado coeficiente angular. Portanto, a alteração na grandeza de $\mathrm{Y}$ por uma unidade de alteração no valor de $X$ permite verificar se as diferenças existentes no incremento de cinco $\mathrm{mg} \mathrm{L}^{-1}$ de alumínio na solução é explicada pelo efeito de tratamento ou devido ao acaso. A análise do coeficientes angular $\left(b_{i}\right)$ pelo teste $t$, de forma a comparar se $b_{i}$ é igual ou diferente de zero, indicou haver significância apenas para as cultivares OR $2 \mathrm{e}$ UFRGS 15 (Tabela 3). A equação de regressão linear para a cultivar OR $2, Y=33,56-1,98 X$, mostra que para cada aumento de um mg L $\mathrm{L}^{-1}$ de alumínio a REC é reduzida em 1,98 mm. Já para a cultivar UFRGS 15, a redução foi de $1,78 \mathrm{~mm}$. Valores de $b$ não significativo pelo teste $\mathrm{t}$ foi observado para as cultivares UPF 16, URS 21, UFRGS 7 e ALBASSUL. Contudo, pode-se verificar que no modelo de regressão linear os genótipos UPF 16 e URS 21 foram tolerantes ao alumínio.

Os valores baixos na REC para os genótipos mais sensíveis permitiram pouca redução quando submetidos às doses mais elevadas de alumínio, não sendo perceptível pelo teste t. Desse modo, mesmo que tivessem todos os genótipos o mesmo comprimento de raiz, apenas quando submetido à solução com alumínio e retornado à solução normal, a maior ou menor retomada de crescimento de raiz indicará de forma efetiva o nível de tolerância característico de cada cultivar.

As variações significativas atribuíveis a dose de alumínio na solução para os genótipos UFRGS 14, UPF 19, UFRGS 19, UFRGS 17, UFRGS 16 e UPF 14, são do tipo quadrática, apresentando coeficientes de regressão $\left(b_{i}\right)$ de $0,07,-0,06,0,06,0,16,-0,08$ e 0,05 , respectivamente, e todos com significância de b pelo teste t.

A equação de regressão do tipo quadrática ( $\mathrm{y}=$ $a+b_{1} x+b_{2} x^{2}$ ) para a cultivar UFRGS 14 pode ser interpretada biologicamente considerando o modelo matemático $-b_{1} / 2 b_{2}$ que, teoricamente $19,68 \mathrm{mg} \mathrm{L}^{-1}$ de alumínio seja a dose que paralisa a REC para o genótipo; assim como para as cultivares UPF $19(13,33$ $\left.\mathrm{mg} \mathrm{L}^{-1}\right)$, UFRGS $17\left(17,96 \mathrm{mg} \mathrm{L}^{-1}\right)$, UFRGS $16(10,63$ $\left.\mathrm{mg} \mathrm{L}^{-1}\right)$ e UPF $14\left(18 \mathrm{mg} \mathrm{L}^{-1} \mathrm{de} \mathrm{Al}^{+}\right)$.

De acordo com a espécie, muitas vezes ocorre dificuldade em visualizar o dano causado pelo elemento químico na raiz, dificultando uma avaliação mais precisa, principalmente em populações altamente segregantes como na geração $F_{2}$, que expressa a máxima variabilidade genética com possibilidades de seleção pelo melhorista, desta forma, o nível de tolerância das plantas ao alumínio em gerações precoces, já pode ser quantitativamente identificado. Neste sentido, avaliar diferentes caracteres existentes tanto na parte aérea como no sistema de raízes pode permitir a seleção indireta para tolerância ao $\mathrm{Al}^{3+} \mathrm{em}$ genótipos de aveia branca. Em arroz VASCONCELOS et al. (2002) determinou que os caracteres morfológicos ligados ao sistema radicular permitiram reconhecer a tolerância ao alumínio entre cultivares tolerantes e sensíveis, sendo o caráter elongação radicular relativa como caráter eficiente na seleção de genótipos tolerantes.

Contudo, a interpretação do nível de tolerância ao alumínio pode ser reforçada pela análise dos testes de médias de acordo com a manifestação biológica do caráter analisado, pois a regressão analisa o genótipo de maneira individual considerando seu desempenho nas três doses em estudo, tendo cada cultivar uma expressão intrínseca de acordo com seu potencial genético. Portanto, interpretando a análise de regressão quadrática e as médias de maneira conjunta, é possível detectar que as cultivares UFRGS 14, UPF 19 e UFRGS 17, são tolerantes ao alumínio.

\section{CONCLUSÕES}

1. As doses de 10,15 e $20 \mathrm{mg} \mathrm{L}^{-1}$ de alumínio em solução nutritiva são altamente eficientes na identificação de genótipos de aveia tolerantes e sensíveis ao alumínio tóxico.

2. As cultivares UPF 16, URS 21, UFRGS 14, UPF 19 e UFRGS 17 expressam tolerância ao alumínio quando avaliados em hidroponia.

\section{AGRADECIMENTOS}

Os autores agradecem a FAPERGS, CNPq e CAPES pelos auxílios recebidos e bolsas de pósgraduação e produtividade em pesquisa.

\section{REFERÊNCIAS}

ANDRADE, J.M.V. Identificação e seleção em casa de vegetação, de genótipos de trigo (Triticum aestivum L.) tolerantes ao alumínio e ao manganês com modificações das características químicas do solo. Porto Alegre. RS. $100 \mathrm{f}$. Dissertação (Mestrado em Agronomia). Curso de PósGraduação em Agronomia), Universidade Federal do Rio Grande do Sul, 1976.

ANIOL, A. Genetics of tolerance to aluminum in wheat (Triticum aestivum L.) Plant and Soil, Wageningen, v.123, n.2, p.223-227, 1990. 
BECKMANN, I. Sobre o cultivo e melhoramento do trigo (Triticum vulgare Vill) no sul do Brasil. Agronomia Sulriograndense, Porto Alegre, v.1, n.1/4, p.64-72. 1954.

BENIN, G.; CARVALHO, F.I.F.; OLIVEIRA, A.C.; SILVA, J.A.G.; LORENCETTI, C.; MAIA, M.B.; MARCHIORO, V.S.; FREITAS, F.; HARTWIG, I. Uma proposta de seleção para caracteres quantitativos e qualitativos em aveia. Ciência Rural, Santa Maria, v.34, n.3, p. 701-706, 2004.

BERTAN, I.; CARVALHO, F.I.F.; OLIVEIRA, A.C.; OLIVEIRA, P.H.; SILVA, J.A.G.; BENIN, G.; SILVA, G.O.; HARTWIG, I.; PADILHA, E.B. Caracteres associados a tolerância ao alumínio tóxico em genótipos de trigos sul brasileiros. Revista Brasileira Agrociência, Pelotas, v.11, n.2, p.149-154, 2005.

CAMARGO, C. E. O.; OLIVEIRA, O. F. Tolerância de cultivares de trigo a diferentes níveis de alumínio em solução nutritiva e no solo. Bragantia, Campinas, v. 40, n.1, p.21 -23, 1981.

DORNELLES, A.L.C.; CARVALHO, F.I.F.; FEDERIZZI, L.C.; SERENO, M.J.C.; AMARAL, A.; MITTELMANN, A. Avaliação simultânea para tolerância ao alumínio e sensibilidade ao ácido giberélico em trigo hexaplóide. Pesquisa Agropecuária Brasileira, Brasília, v.32, n.9, p.893-896, 1997.

FLOSS, E.L.; BAIER, A.C.; EICHLER, L.; GOELLNER, C.I.; FONTANELI, R.S. Oat production and breeding in South Brazil. Winnipeg, Oat Newsletter, 33: P. 11-13, 1983.

KUMAR, P.B.A.N.; DUSHENKOV, V.; MOTTO, H. Phytoextraction: The use of plants to remove heavy metals from soils. Environmental ScienceTecnology, Washington, v. 29, p.1232-1238, 1995.

MINELLA, E.; SORRELS, M.E. Aluminum tolerance in barley: genetic relationships among genotypes of diverse origin. Crop Science, Madison, v. 32, n.3, p. 593-598, 1992.

MOORE, D.P.; KRONSTAD, W.E.; METZEGER, R.J. Screening wheat for aluminum tolerance. In: WORKSHOP ON PLANT ADAPTATION TO MINERAL STRESS IN PROBLEM SOILS, Beltsville, 1976. Proceedings. Ithaca: Cornell University, 1976. p.287-295.
OLIVEIRA, P.H. de. Herança genética e mapeamento molecular da tolerância à toxidade do alumínio em aveia (Avena sativa L.). Porto alegre, 2002, 102p. Tese (Doutorado em Agronomia) - Universidade Federal do Rio Grande do Sul-UFRGS.

RIEDE, C.R.; ANDERSON, J. A. Linkage of RFLP markers to aluminum tolerance gene in wheat. Crop Science, Madison, v.36, n.4, p.905-909, 1996.

SÁNCHES-CHACÓN, C.D.; FEDERIZZI, L.C.; MILACH, S.C.K.; PACHECO, M.T. Variabilidade genética e herança da tolerância à toxicidade do alumínio em aveia. Pesquisa Agropecuária Brasileira, Brasília, v.35, n.9, p.1798-1808, 2000.

SILVA, J.B.C. da; NOVAIS, R.F. de; SEDIYAMA, C.S. Comportamento de genótipos de soja em solo com alta saturação de alumínio. Pesquisa Agropecuária Brasileira, Brasília, v.19, n.3, p.287-298, 1984.

SILVA, J.A.G.; CARVALHO, F.I.F.; OLIVEIRA, A.C.; SILVA, S.A.; MARCHIORO, V.S.; LORENCETTI, C.; BENIN, G.; SCHIMDT, D.A.M.; HARTWIG, I. Trigos di-haplóides com potencial para tolerância a toxicidade ao alumínio e a sensibilidade ao ácido giberélico em cultivo hidropônico. Revista Brasileira de Agrociência, Pelotas, v.10, n.1, p.37-41, 2004.

STEEL, R.G.D.; TORRIE, J.H. Principles and procedures of statistics: a biometrical approach. New York: MacGraw-Hill Book Company, 1980. 633 p.

VASCONCELOS, S.S.; ROSSIELO, R.O.P.; JACOB-NETO, J. Parâmetros morfológicos para estabelecer tolerância diferencial à toxicidade de alumínio em cultivares de arroz. Pesquisa Agropecuária Brasileira, Brasília, v.37, n.3, p. 357$363,2002$. 